\title{
Correction to: Potential impacts of extreme weather events in main maize (Zea mays $L$.) producing areas of South Africa under rainfed conditions
}

\author{
Robert Mangani ${ }^{1}$ • Eyob H. Tesfamariam ${ }^{1}$. Christien J. Engelbrecht ${ }^{2,3} \cdot$ Gianni Bellocchi $^{4}$ • Abubeker Hassen ${ }^{5}$. \\ Tshepiso Mangani ${ }^{2}$
}

Published online: 10 May 2019

(C) Springer-Verlag GmbH Germany, part of Springer Nature 2019

\section{Correction to: Regional Environmental Change} https://doi.org/10.1007/s10113-019-01486-8

In the original article, the panels of Figure 5 were also shown in Figure 6. The figure caption was correct.

The original article has been corrected.

Publisher's note Springer Nature remains neutral with regard to jurisdictional claims in published maps and institutional affiliations.

The online version of the original article can be found at https://doi.org/ 10.1007/s10113-019-01486-8

Robert Mangani

manganirob@gmail.com

Eyob H. Tesfamariam

eyob.tesfamariam@up.ac.za

1 Department of Plant and Soil Science, University of Pretoria, Private Bag x20, Hatfield, Pretoria 0028, South Africa

2 Institute for Soil, Climate and Water, Agricultural Research Council, Pretoria, South Africa

3 Department of Geography, Geoinformatics and Meteorology, University of Pretoria, Private Bag x20, Hatfield, Pretoria 0028, South Africa

4 UREP, INRA 63000, Clermont-Ferrand, France

5 Department of Animal and Wildlife Sciences, Faculty of Natural- and Agricultural Sciences, University of Pretoria, Private Bag x20, Hatfield 0028, Pretoria 0002, South Africa 

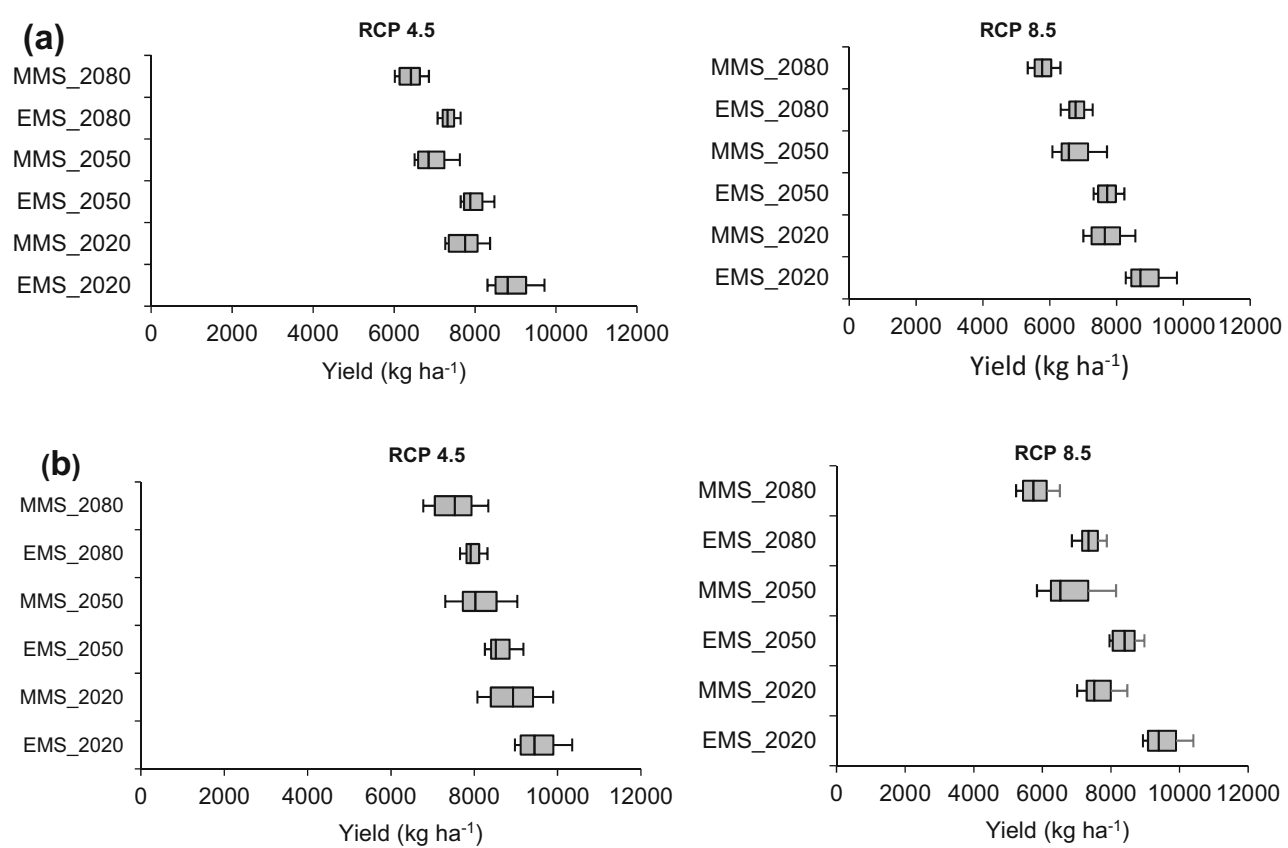

\section{(c)}

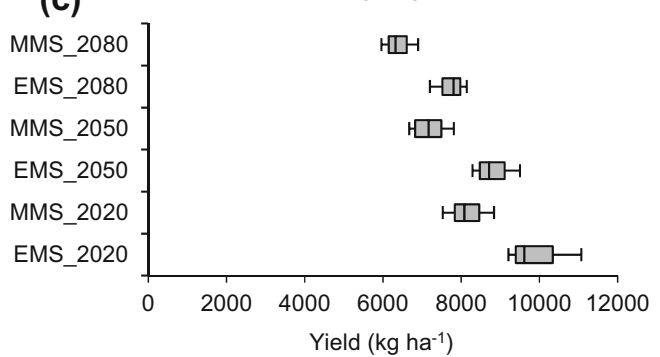

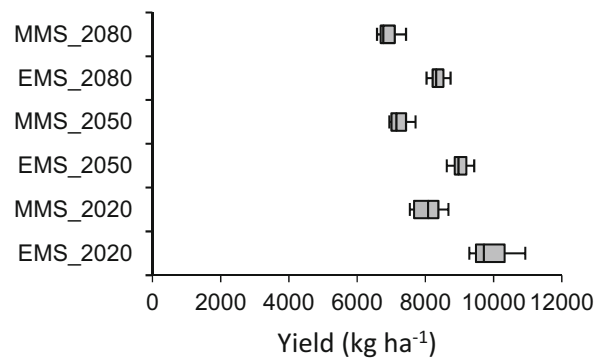

three sites: a Bloemfontein, b Lichtenburg, and c Nelspruit. Vertical lines in shaded boxes are the median; whiskers represent the upper and lower quartiles
Fig. 6 Box plots comparing the grain yield of simulated rain fed maize yields under different time horizons using the existing (EMS) and modified (MMS) CropSyst modelling solutions for different time horizons at 